Original Article (short paper)

\title{
Effects of Acute Physical Exercise and Television Viewing on Mood in Older Active Women
}

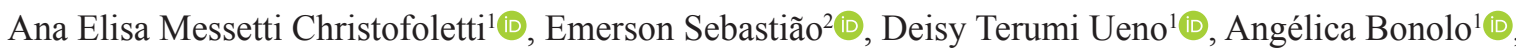 \\ Silvia Deutsch ${ }^{1}$ (1) , Priscila Missaki Nakamura ${ }^{1,3}$ (]) \\ ${ }^{1}$ Universidade Estadual Paulista (UNESP), Instituto de Biociências, Departamento de Educação Física, \\ Programa de Pós Graduação em Ciências da Motricidade, Rio Claro, SP, Brazil; ${ }^{2}$ Northern Illinois \\ University, Department of Kinesiology and Physical Education, DeKalb, IL, United States; ${ }^{3}$ Instituto \\ Federal de Educação, Ciência e Tecnologia. IFSULDEMINAS, Muzambinho, MG, Brazil
}

\begin{abstract}
Aim: Due to the increased prevalence of mood disorders and the detrimental effects of sedentary behavior on health, a better understanding of the association between physical exercise (PE), TV viewing and mood in older adults is paramount. This is based on the fact that mood has been recognized as an important predictor of longevity, well-being, and quality of life. This study examined the effects of an acute bout of physical exercise (PE) and television viewing (TV) on positive and negative mood states of older active women. Methods: Fifty-four women aged 60 years and older were asked to complete the Abbreviated and Illustrated Mood States Inventory (LEA-RI) before and immediatly after two distinct activities: 1) single bout of PE; and 2) a single bout of TV. Participants further completed questionnaires to provide information on demographics, physical activity and sedentary behavior for sample characterization. Differences between conditions (PE and TV) on positive and negative mood state were analyzed using repeated measures ANOVA followed by paired sample $t$-test adopting a significance level of $P<.05$. Results: Positive mood states significantly increased for the PE $(P=0.001)$ but not for the TV condition $(P=0.388)$. Negative mood states significantly increased for the PE condition $(P=0.003)$ but significantly reduced for the TV condition $(P=0.011)$. Conclusions: The findings suggest that a single bout of PE may be more beneficial to improve positive mood compared to a single bout of TV. However, the TV may be able to reduce negative mood in older active women.
\end{abstract}

Keywords: active lifestyle, elderly, mood, motor activity, sedentary behavior.

\section{Introduction}

Human beings are living longer than ever and much of this success can be attributed to public health initiatives and advances in medicine and technology ${ }^{1}$. Despite the gains in life expectancy, longevity is not synonymous with good health and/or quality of life $^{2}$. The aging process is accompanied by a physiological decline that makes older adults more vulnerable to developing chronic diseases and less able to perform activities daily living ${ }^{3}$. In addition to physical decline occurring with aging, the prevalence of mood disorders tends to increase in the older adult population ${ }^{4}$. Age-related changes observed in the physical, mental and social domains often present challenges to emotional stability ${ }^{5}$.

There is a growing interest in the study of mood in the older adult population. This is based on the fact that mood has been recognized as an important predictor of longevity, well-being, and quality of life in this group ${ }^{6}$. This is further based on the strong association observed between positive mood and favorable health and health behavior outcomes such as physical activity? ${ }^{7}$. The mood is defined as a transient and fluctuating affective state (i.e., positive or negative) and differs from emotion by its duration and intensit ${ }^{8}$. Researchers have demonstrated that different approaches can be adopted to regulate mood but are not limited to: listening to music, seeking social interaction and engaging in physical activity/ exercise activities ${ }^{9-11}$. However, very little is known about the effects of a sedentary activity such as television viewing on mood states in this population. This is important because of the compelling evidence of the detrimental effects of sedentary behavior ${ }^{12}$ such TV time on older adults' physical health; but its effect on psychological/mental health (e.g., mood) remains largely unknown. Furthermore, this is also important as TV viewing is highly prevalent among older adults and comprises a significant portion of their waking hours ${ }^{13}$. Researchers observed that over $40 \%$ of older Brazilian adults engage in 2 or more hours of TV viewing per day, with older adults reporting an average of 5 hours per day ${ }^{14}$. In developed countries, there is evidence suggesting that older Japanese adults spend about 14 hours per week watching $\mathrm{TV}^{(14)}$ and older American adults over 5 hours per day ${ }^{15}$. There is further evidence suggesting that watching $\mathrm{TV}$-shows that involve chaos, violence and vulnerability may cause detrimental effects on psychological well-being ${ }^{16}$. To this end, a better 
understanding of the association between physical exercise (PE), TV viewing and mood in older adults is paramount due to the increased prevalence of mood disorders in this population and the elevated hours of TV viewing spent by this population.

To this end, the present study examined the effects of an acute bout of PE and TV viewing on mood states of older women. We hypothesized that PE will improve participants' mood in greater magnitude compared to TV viewing.

\section{Material and Methods}

\section{Study design}

This study involved a repeated measures design targeting older adults aged 60 years and over. The research protocol was approved by the Institutional Review Board of the Sao Paulo State University (1.111.021) and informed consent was signed by each participant before data collection.

\section{Participants}

Our convenience sample was recruited from the "Programa de Atividade Física para a Terceira Idade - PROFIT" (Physical Activity Program for Seniors). Briefly, PROFIT is an outreach exercise program offered by the Department of Physical Education of Sao Paulo State University at Rio Claro for older adults living in the surrounding community. The main goal of the program is to provide low-cost, guided and structured exercise activities to improve the health and well-being of the participants. Older adults participating in the program can opt to participate in one of the four exercise programs offered (i.e., general physical activity, dance, aerobics, and resistance training). All modalities are offered 2-3 times per week with 60 minutes duration each session. A total of 148 females and 21 males participate in the program. Because of the low number of males enrolled in the PROFIT and due to the potential differential response on the main outcome variable (i.e., mood state), we opted to include only women. All 148 women were invited to participate and 91 (61.48\%) accepted the invitation. Fifty-four out of 91 completed all required measurements and were eligible to participate based on the inclusion criteria (figure 1).

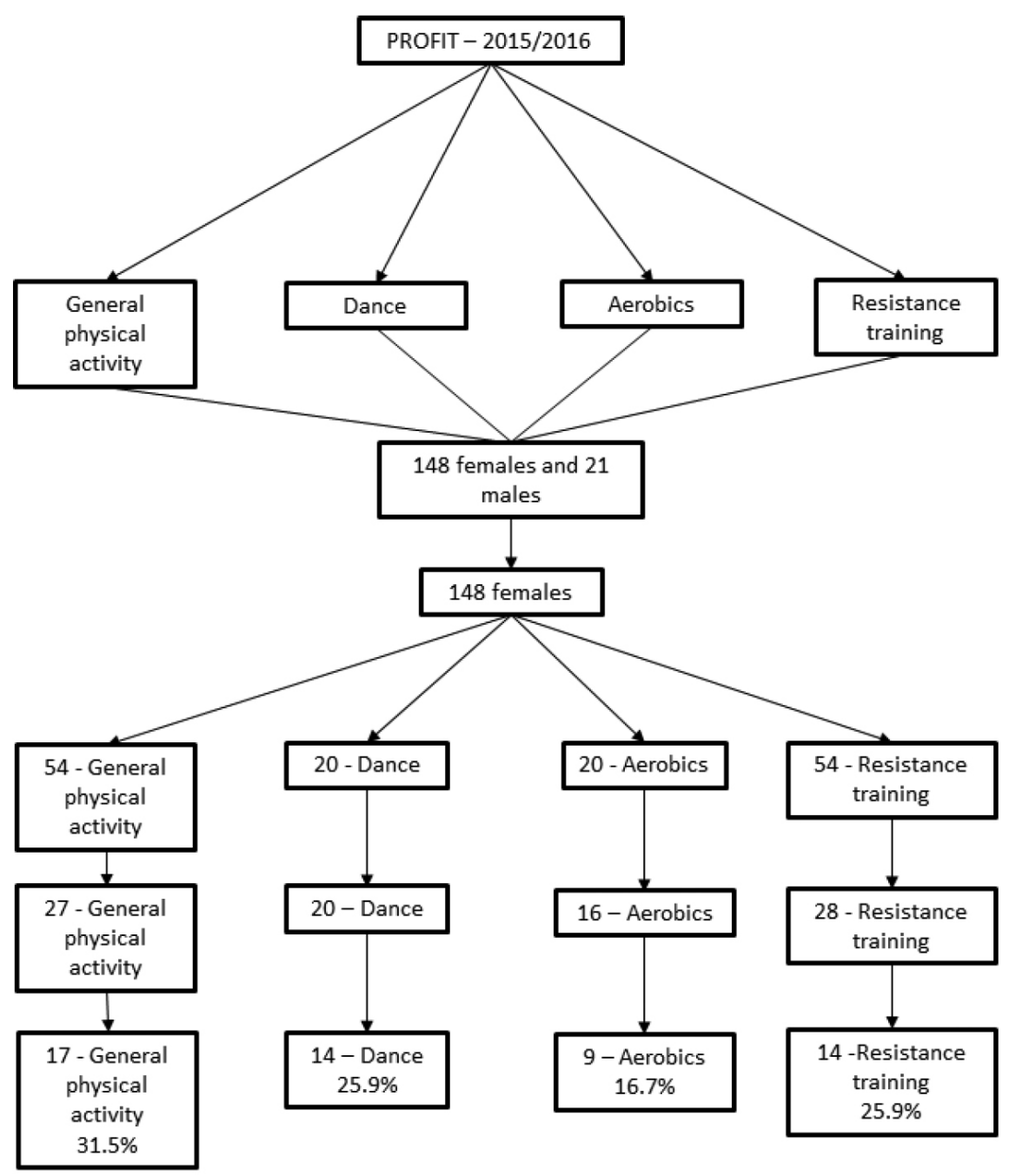

Figure 1. Flow diagram for sample selection 


\section{Measures}

Mood states. Mood states were measured using the "Lista de Estados de Animo Reduzida e Ilustrada - LEA-RI' (Abbreviated and Illustrated Mood States Inventory $)^{(17)}$, which is a valid instrument to measure mood in older adults ${ }^{(17)}$. This instrument is comprised by a list of 14 adjectives which are equally divided into two subscales: positive (i.e., happy, active, calm, light, pleasant, full of energy and spiritual) and negative (i.e., sad, agitated, heavy, unpleasant, afraid and useless) adjectives. The inventory further has illustrations/figures representing facial expressions for each of the 14 adjectives that helps in its administration. The LEA-RI uses a Likert scale (i.e., very strong $=4$, strong $=3$, weak $=2$ and very weak $=1$ ) to produce a score for each subscale (i.e., positive and negative adjectives), which is given by the sum of points obtained for each adjective. For the purpose of this study we calculated and analyzed a total score for each subscale (i.e., positive and negative mood), as employed elsewhere ${ }^{(18)}$.

\section{Other measures}

A collection of other measures were adopted with the purpose of sample characterization. We collected information on physical activity and sedentary behavior. Physical activity was assessed using the widely accepted International Physical Activity Questionnaire (IPAQ - short version) ${ }^{(19)}$; which has been validated to be used in older Brazilian adults ${ }^{(20)}$. Time spent in physical activity was expressed in minutes per week and was given by the sum of minutes spent in walking, moderate and vigorous physical activity. Sedentary behavior was assessed using the Sedentary Behavior Questionnaire ${ }^{(21)}$; which was previously validated in a cohort study involving adults and the older adults ${ }^{(21)}$. This instrument is able to gather information on the amount of sitting time of the participants in different situations (i.e., TV time, computer, work, studies and transportation). The score is calculated by summing the minutes reported by each participant during a weekday and it is expressed in minutes per day. A demographic and clinical questionnaire developed to attend the purpose of this study was used to gather information on age, diagnosed chronic diseases, level of education and income level ${ }^{(22)}$.

\section{Procedures}

Participants in this study underwent both protocols (i.e, single bout of PE and TV viewing) which were conducted in the same order for all participants but on separate days. In the first day, participants completed all questionnaires related to sample characterization with the assistance of six experienced assessors who were further trained in the specific measures of the present study. The assessors were responsible for reading each question to participants and clarifying any potential question. This portion took an average of 30 minutes to be completed. On the second day, participants completed the LEA-RI immediately before and after engaging in one session of the exercise modality they participate in through PROFIT. Participants were previously instructed on how to complete the instrument and assessors were present in the room to clarify any possible question. On the third day, participants completed the LEA-RI immediately before and after a single bout of TV viewing that was performed in their own home in a day they did not exercise at the PROFIT. The completed LEA-RI was then retrieved by the assessor for analysis. It is important to clarify that for the third day of assessment (i.e., TV viewing).

\section{Physical exercise}

The exercise modalities offered by PROFIT take place in the Department of Physical Education of the Sao Paulo State University, Rio Claro, Brazil. The exercise sessions last 60 minutes and are conducted in the early morning period from 7:00 to 8:00 AM. Each modality is led by an instructor and has different characteristics. However, regardless tof he exercise modality, all of them are separated into three phases: warm up (initial 10 minutes), main part (40 minutes) and cool down (final 10 minutes) and focus on improving older adults' functional fitness (i.e., cardiorespiratory capacity, muscle strength, flexibility, balance, agility and coordination).

\section{TV viewing (sedentary behavior)}

This involved older adults watching a TV show of their choice for approximately 60 minutes (i.e., the same duration of the exercise sessions in PROFIT). Of note, the show chosen by the participants and the time of the day the show was watched were not systematically controlled.

\section{Data analysis}

Data were analyzed using SPSS version 22 (SPSS Inc.; IBM Corp. Armonk, NY) and statistical significance was set at $P<.05$. Descriptive statistics (i.e., mean and standard deviation) was used to report demographic, health behavior (i.e., physical activity and sedentary time) and mood state scores. We further employed a two-way repeated measures ANOVA followed by paired sample t-test to examine potential changes on mood state scores over time between conditions (i.e., PE, TV viewing). The $\eta^{2}$ was used as measure of the magnitude of differences. Of note, $\eta^{2}$ is analogous with $\mathrm{R}^{2}$ and reflects variance explained in the outcome variable.

\section{Results}

\section{Demographics and health behavior}

A detailed description of the 54 older women included in this study is given in table 1 . In terms of physical activity, 
participants reported an average of $1550.0 \pm 1222.34$ minutes per week and an average of $5.0 \pm 2.4$ hours per day of sedentary activities. Participants had more than 11 year of study (41\%) and approximately $57 \%$ were classified as middle class income.

Table 1: General characteristics of the sample (age, physical activity and sedentary behaviour).

\begin{tabular}{lc}
\hline \multicolumn{1}{c}{ Variable $($ mean \pm SD) } & Total $(\mathbf{n}=\mathbf{5 4})$ \\
\hline Age, years & $67.9 \pm 5.7$ \\
Physical Activity, min.week & $1550.0 \pm 1222.34$ \\
Sedentary Behavior, hour.day & \\
Television & $3.1 \pm 1.3$ \\
Computer & $0.8 \pm 1.2$ \\
Work & $0.3 \pm 0.9$ \\
Study & $0.1 \pm 0.5$ \\
Transport & $0.8 \pm 0.9$ \\
Total & $5.0 \pm 2.4$ \\
\hline
\end{tabular}

\section{Mood States}

Findings for the subscale positive mood as separated by condition (i.e., PE and TV viewing) is displayed in figure 2. Briefly, results revealed a significant increase in positive mood states in the PE condition (pre: 20.35 [19.4 - 21.2] vs. post: 22.3 [21.4-23.2]; $\mathrm{t}(53)=-3.470 ; \mathrm{P}=0.001$; but no siginificant changes were obseved for the TV vieweing condition (pre: 18.87 [17.6 $20.14]$ vs. post: $19.44[18.3-20.5] ; \mathrm{t}(53)=-0.870 ; P=0.388$; from pre to post-assessments.

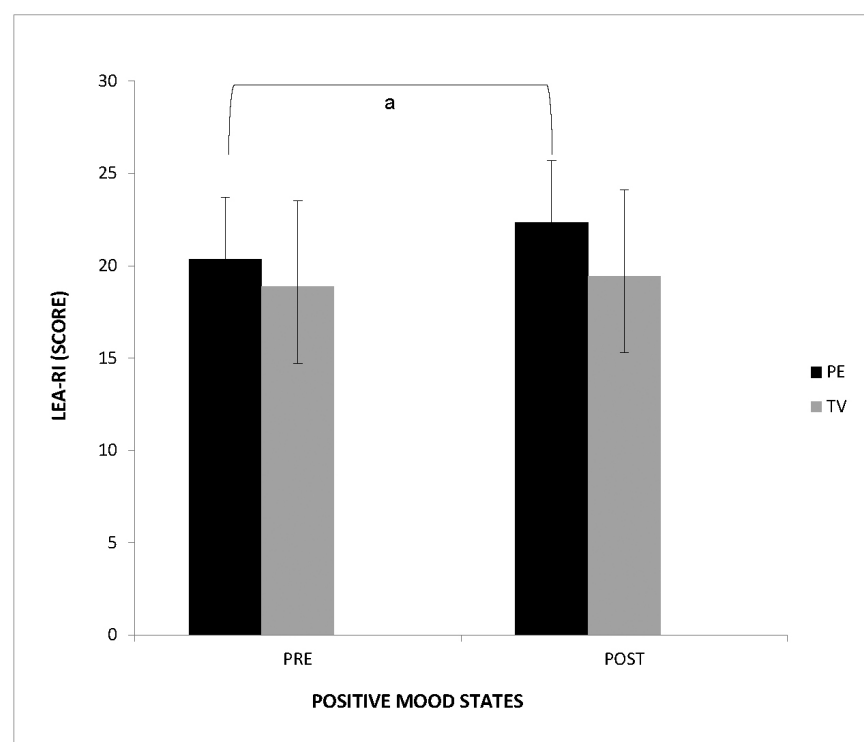

Figure 2. Mean and standard deviation of pre- and post-scores of positive mood states assessed using the Abbreviated and Illustrated Mood States Inventory (LEA-RI) between physical exercise (PE) and TV viewing conditions in older active women $(\mathrm{n}=54$, Rio Claro $-\mathrm{SP}$, 2015, 2016); ${ }^{\text {a }}$ paired sample $t$-test $(P<.05)$

Findings for the subscale negative mood as separated by condition (i.e., $\mathrm{PE}$ and $\mathrm{TV}$ viewing) is displayed in figure 3. Briefly, results revealed a significant increase in negative mood states for the PE condition (pre: 9.5 [8.9 - 10.1] vs. post: 10.5 $[9.6-11.5] ; \mathrm{t}(53)=-2.163 ; \mathrm{P}=0.03$; and significant decrease for the TV viewing condition (pre: 10.7 [9.5-11.9] vs. post: 9.4 [8.6- 10.2]; $\mathrm{t}(53)=2.647 ; \mathrm{P}=0.011$; from pre to post-assessments.

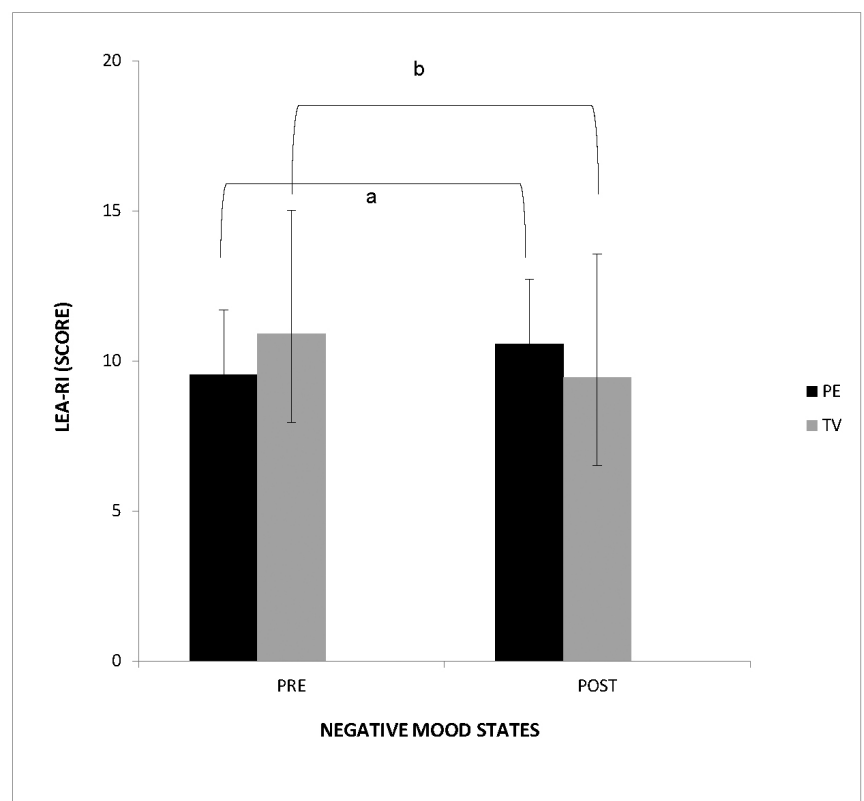

Figure 3. Mean and standard deviation of pre- and post-scores of negative mood states assessed using the Abbreviated and Illustrated Mood States Inventory (LEA-RI) between physical exercise (PE) and $\mathrm{TV}$ viewing conditions in older active women $(\mathrm{n}=54$, Rio Claro - SP, 2015, 2016). a,b paired sample $t$-test $(P<.05)$.

\section{Discussion}

This study examined the acute effect of a bout of PE and TV viewing on mood states (i.e., positive and negative) in older active women. The main findings of this study were: a) an acute bout of PE was effective in significantly improving positive mood scores but no significant changes in positive mood scores were observed for the TV viewing condition and; b) an acute bout of PE significantly increased negative mood scores in older active women while an acute bout of TV viewing significantly reduced negative mood scores in this population.

Our results that positive mood improved after an acute bout of PE in older women corroborate the findings of previous studies ${ }^{(7,23)}$. For instance, a study conducted with adults reported that adult workers who spend all day sitting but walk at moderate intensity during 30 minutes in the morning or perform 6 minutes of moderate walking on the treadmill every one hour of work presented greater improvements in mood compared to workers who remained in sedentary behavior all day ${ }^{(24)}$. Similarly, studies conducted on older adults suggest that physical activity has a positive impact on mood in this population. Researchers observed that older adults who engage in regular physical activity present with better mood compared with those who engage in more sedentary lifestyles ${ }^{(7,8)}$. Further, researchers have demonstrated improvements in mood states in older adults following a single bout of resistance training that lasted for about one hour ${ }^{(23)}$. 
Collectively, these findings reinforce physical activity/exercise as an effective approach to improve mood among older adults. Contrary to our expectations and previous work ${ }^{(25)}$ we further observed a significant increase in negative mood states after the acute bout of PE. A possible explanation could be related to the fact that participants may have felt some level of frustration as the exercise session came to the end. Participants in this study were active older women and members of PROFIT for many years. This indirectly demonstrates commitment and enjoyment for exercise. For some older adults participating in the program, coming to the exercise sessions three times per week may be their only moment for socialization and fun. Thus, this frustation may have turned into momentary negative effects and as we assess mood immediately after the exercise session, the instrument used was sensitive enough to capture this change. However, it is important to note that the negative mood scores (pre and post) were kept low.

In terms of TV viewing and mood, it is believed that excessive TV watching can be detrimental for psychological health when programs reflect scenes of violence and chaos. On the other hand, TV shows related to amusements may positively impact mood ${ }^{(16)}$. Our findings demonstrated that an acute bout of TV viewing did not significantly affect positive mood but was able to significantly reduce scores of negative moods in older active women. It did not come to a surprise as previous work demonstrated that shows related to entertainment and information content enhanced $\operatorname{mood}^{(16)}$. A plausible explanation could be related to the fact that the TV show watched by our participants was able to cause feelings of pleasure and calmness (i.e., relaxation) that translated into a reduced negative mood. However, the type of show was not collected in our study. Nevertheless, caution is needed when attempting to utilize the above information to promote mental health in older adults due to the emerging evidence of prolonged periods of sedentary time on physical health.

Our findings corroborate previous work suggesting that a physically active lifestyle is beneficial for improving mood ${ }^{(26)}$, but little is known about the potential effect of sedentary activity, such as TV watching, on mood in the active older adults. Researchers comparing mood between active and inactive older adults have observed better mood in those who are active compared with their inactive counterparts ${ }^{(7)}$. However, the present study is the first to investigate the potential effect of an acute bout of sedentary activity (i.e., TV watching) on mood in older women. This is important due to the known detrimental effects of prolonged periods of sedentary behavior on physical health and due to the challenges associated with mood disorders in adults, but specifically, in the older adult population. As previously stated, mood is a factor with the potential to negatively affect the quality of life and well-being in this population. Mood imbalances may result in depression and social isolation, which are commonly observed later in life ${ }^{(9)}$.

The results of this study should be interpreted with caution due to limitations. The participants enrolled in this study, comprised a convenience sample, that has been regular exercisers and we did not randomize the order of the activities/conditions. Further, we did not control for the type of TV show participants watched. The fact that our participants were regular exercisers could have hidden the real effect of an acute bout of PE or TV viewing on the mood. This is because they could have already been building the benefits of exercise on mood over time through getting more physically/mentally fit based on regular exercise participation. Of note, our participants have been engaged in the PROFIT for at least 6 months. Moreover, as previously mentioned, different TV shows may engender different responses on mood as previously demonstrated ${ }^{(27)}$. We did not have an inactive group to compare our results as this would be interesting to identify whether older active women respond differently than physically inactive women on mood in response to a bout of exercise or TV viewing. Future studies should examine potential differences in the acute and chronic responses of a single bout of PE and TV viewing (controlling for the TV show watched) in older inactive/sedentary women, attempting to randomize the order of the activities. Despite the limitations, we were able to provide valuable information related to the acute effect of PE and TV viewing on mood of older active women that complement previous findings observed by researchers on the chronic effects of sitting time watching $\mathrm{TV}^{(14-16)}$. This is important due to the high rates of mood disorders and their well-known consequences as observed in this age group.

In summary, our findings suggest that PE is more effective to improve positive mood compared with TV viewing in older active women. However, an acute bout of PE may engender small changes in the negative mood in this population. In terms of TV viewing, our results suggest that an acute bout of this activity may reduce negative mood but has no effect on positive mood. Our findings may be used to promote physical activity among older adults and to reduce the time of this population spending watching TV.

\section{References}

1. Vos T, Flaxman AD, Naghavi M, Lozano R, Michaud C, Ezzati M, et al. Years lived with disability ( YLDs ) for 1160 sequelae of 289 diseases and injuries $1990-2010$ : a systematic analysis for the Global Burden of Disease Study 2010. 2014;2163-96.

2. Romero DE, Leite I da C, Szwarcwald CL. Healthy life expectancy in Brazil: applying the Sullivan method. Cad Saude Publica. 2005;21(suppl 1):S7-18.

3. Del Duca GF, Silva MC da, Hallal PC. Incapacidade funcional para atividades básicas e instrumentais da vida diária em idosos TT. Rev Saude Publica. 2009;43(5):796-805.

4. Vagetti GC, Filho VCB, Moreira B. Association between physical activity and quality of life in the elderly : a systematic review , 2000-2012. Rev Bras Psiquiatr. 2014;36:76-88.

5. Penna FB, Santo FH do E. O movimento das emoções na vida dos idosos: um estudo com um grupo da terceira idade. Rev Eletrônica Enferm. 2006;8(1):17-24.

6. Nahas MV, Barros MVG FV. O pentáculo do bem-estar: base conceitual para avaliação do estilo de vida de indivíduos e grupos. Rev Bras Ativ Fís Saúde. 2000;5(2):48-59.

7. Arent SM, Landers DM EJ. The Effects of Exercise on Mood in Older Adults: A Meta-Analytic Review. J Aging Phys Act. 2000;8:407-30. 
8. Williams P, Lord SR. Effects of group exercise on cognitive functioning and mood in older women. Aust N Z J Public Heal. 1997;21(1):45-52.

9. Mammen G, Faulkner G. Physical activity and the prevention of depression: A systematic review of prospective studies. Am J Prev Med. 2013;45(5):649-57.

10. Prado, Alexandre Konig Garcia; Schwartz, Gisele Maria; Tanaka, Kátia; Doll, Mônica Silva; Gonçalves, Raquel; Gobbi S. Efeito agudo e crônico de um programa de atividades físicas realizado no "playground da longevidade" nos estados de ânimo de idosos. Rev da Educ Física/UEM. 2010;21(3):517-26.

11. Barton J, Griffin M, Pretty J. Exercise-, nature- and socially interactive-based initiatives improve mood and self-esteem in the clinical population. Perspect Public Health. 2012;132(2):89-96.

12. Manas A, del Pozo-Cruz B, García-García FJ, Guadalupe-Grau A, Ara I. Role of objectively measured sedentary behaviour in physical performance, frailty and mortality among older adults: A short systematic review. Eur J Sport Sci. 2017;17(7):940-53.

13. Brasil, Secretaria da Comunicação Social da Presidência. Pesquisa brasileira de mídia 2016: hábitos de consumo de mídia pela população brasileira. 2016. 162 p.

14. Inoue $\mathrm{S}$, Sugiyama T, Takamiya T, Oka K, Owen N, Shimomitsu T. Television Viewing Time is Associated with Overweight/Obesity Among Older Adults, Independent of Meeting Physical Activity and Health Guidelines. J Epidemiol. 2012;22(1):50-6.

15. Keadle SK, Arem H, Moore SC, Sampson JN, Matthews CE. Impact of changes in television viewing time and physical activity on longevity: A prospective cohort study. Int J Behav Nutr Phys Act. 2015;12(1):1-11.

16. Jahangir SF, Nawaz N. Effects of Media (Television) on Mental Health. FWU J Soc Sci. 2014;8(1):97-102.

17. Volp CM. LEA para populações diversas. Rio Claro UNESP, 2000. Relatório Trienal apresentado à CPRT, UNESP, 2000.

18. Nakamura PM, Deustch S, Kokubun E. Influência da música preferida e não preferida no estado de ânimo e no desempenho de exercícios realizados na intensidade vigorosa. Rev Bras Educ Física e Esporte. 2008;404(4):247-55.

19. Matsudo S, Araújo T, Matsudo V, Andrade D, Andrade E, Oliveira LC BG. Questionário Internacional de Atividade Física (IPAQ): estudo de validade e reprodutibilidade no Brasil. Rev Atividade Física Saúde. 2001;6(2):5-18.

20. Benedetti TB, Mazo GZ, Barros MVG. Aplicação do Questionário Internacional de Atividades Físicas para avaliação do nível de atividades físicas de mulheres idosas : validade concorrente e reprodutibilidade teste-reteste. Rev Bras Ciência e Mov. 2004;12(1):25-34.

21. Mielke GI. Comportamento sedentário em adultos. Diss Mestr Univ Fed Pelotas. 2012;1-149.

22. Associação Brasileira de Empresas de Pesquisa. Critério de classificação econômica Brasil. Critério Brasil 2015 e atualização da distribuição de classes para 2016. Critério Classif econômica Bras. 2016;1-6.
23. Gobbi S, Ribeiro C, Oliveira SRG De, Junior ACDQ. Efeitos da dança e do treinamento com pesos nos estados de ânimo de idosos. Rev da Educ Física/UEM. 2007;18(2):161-8.

24. Bergouignan A, Legget KT, De Jong N, Kealey E, Nikolovski J, Groppel JL, et al. Effect of frequent interruptions of prolonged sitting on self-perceived levels of energy, mood, food cravings and cognitive function. Int J Behav Nutr Phys Act. 2016;13(1).

25. Gobbi S, Corazza DI, Costa JLR, Ueno DT, Gobbi LTB. Atividade física e saúde no envelhecimento: a experiência do Programa de Atividade Física para a Terceira Idade (PROFIT). Promoção do envelhecimento saudável em Diadema. 2013. 283-296 p.

26. Berger BG, Motl RW. Exercise and mood: A selective review and synthesis of research employing the profile of mood states. J Appl Sport Psychol. 2000;12(1):69-92.

27. Farhana Jahangir S, Nawaz N, Khan N. Effects of Media (Television) on Mental Health. FWU J Soc Sci. 2014;8(1):97-107.

\section{Acknowledgments}

The authors thank the Department of Physical Education of the Sao Paulo State University at Rio Claro, Brazil, the participants of the Physical Activity Program for the Elderly (PROFIT), the support of Coordination for the Improvement of Higher Education Personnel (CAPES), and Luis Hernandez from the Department of Kinesiology and Physical Education of Northern Illinois University for proofreading the present manuscript.

\section{Corresponding author}

Ana Elisa Christofoletti,

Department of Physical Education. São Paulo State University - UNESP Avenida 24-A, 1515, Bela Vista - Rio Claro - 13506-900, Rio Claro, Sao Paulo, Brazil.

Email: anaelisamchr@hotmail.com; anaelisamchr@gmail.com

Manuscript received on September 3, 2018

Manuscript accepted on November 22, 2018

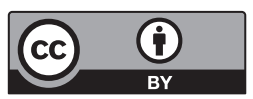

Motriz. The Journal of Physical Education. UNESP. Rio Claro, SP, Brazil - eISSN: 1980-6574 - under a license Creative Commons - Version 4.0 